
Motrivivência
v. 28,
n. 49 ,
p. $227-241$
dezembro/2016

\title{
A BNCC EM DISCUSSÃO NA FORMAÇÃO CONTINUADA DE PROFESSORES DE EDUCAÇÃO FÍSICA: um relato de experiência - Natal/RN
}

\author{
Dianne Cristina Souza de Sena \\ Wanessa Cristina Maranhão de Freitas Rodrigues ${ }^{2}$ \\ Jonas Morais Sobrinho ${ }^{3}$ \\ Matheus Jancy Bezerra Dantas ${ }^{4}$ \\ Christuan Giullianno de Lara Souza Silva ${ }^{5}$
}

\begin{abstract}
RESUMO
Após o lançamento do Portal da Base Nacional Comum Curricular (BNCC) e a abertura para contribuições, uma proposta de cronograma em âmbito estadual foi estabelecida para que o estado do Rio Grande do Norte e seus municípios pudessem se organizar, no intuito de mobilizar seus educadores, estimulando-os a contribuir na construção deste documento. Buscando atender estas demandas, propusemos, na condição de grupo de assessoramento pedagógico da equipe de Educação Física da Secretaria Municipal de Educação do Natal, o Fórum de Discussão sobre a BNCC, através do programa de Formação Continuada para professores em exercício desta Secretaria. Articulamos a realização do Fórum com o corpo docente do Departamento de Educação Física da Universidade Federal do Rio Grande do Norte. Assim, o Fórum objetivou realizar uma reflexão crítica sobre a BNCC, além de trazer o professor como colaborador desta construção democrática.
\end{abstract}

Palavras chave: Base Nacional; Formação Continuada; Educação Física Escolar.

1 Mestre em Educação. Professora da Secretaria Municipal de Educação (SME). Membro do Laboratório de Estudos em Educação Física, Esporte e Mídia da Universidade Federal do Rio Grande do Norte (LEFEM/UFRN). Nova Parnamirim/Rio Grande do Norte, Brasil. E-mail: diannesena@hotmail.com

2 Mestranda em Educação Física. Trabalha na Secretaria Municipal de Educação (SME). Membro do Grupo de Estudos Corpo e Cultura de Movimento da Universidade Federal do Rio Grande do Norte (GEPEC/ UFRN). Natal/Rio Grande do Norte, Brasil. E-mail: wanessacristy@hotmail.com

3 Mestrando em Educação. Professor do ensino básico e tecnológico do Instituto Federal de Educação, Ciência e Tecnologia do Rio Grande do Norte (IFRN). Membro do Grupo de Estudos Corpo e Cultura de Movimento da Universidade Federal do Rio Grande do Norte (GEPEC/ UFRN). Natal/Rio Grande do Norte, Brasil.

E-mail: jonas.sobrinho@hotmail.com

4 Especialista em Corpo e Cultura de Movimento. Trabalha na Secretaria Municipal de Educação (SME). Membro do Laboratório de Atividade Motora Adaptada da Universidade Estadual de Campinas (UNICAMP). Natal/Rio Grande do Norte, Brasil. E-mail: matheusjancy@gmail.com

5 Mestre em Educação Física. Trabalha na Secretaria Municipal de Educação (SME). Membro do Grupo de pesquisa Corpo, Fenomenologia e Movimento - Estesia da Universidade Federal do Rio Grande do Norte (UFRN). Natal/ Rio Grande do Norte, Brasil. E-mail: cglsouzasilva@gmail.com 


\section{INTRODUÇÃO}

O presente texto traz as contribuições ao atual debate da construção da Base Nacional Comum Curricular - BNCC, no tocante ao componente curricular Educação Física. O movimento promovido em torno da BNCC traz implicações importantes que atravessam, desde as orientações da atual política educacional em torno da área, até a sua materialização nos espaços formais de ensino. A Educação Física possui especificidades que devem ser mediadas entre as reais necessidades da comunidade escolar e os anseios advindos desse importante movimento de colaboração entre diferentes segmentos da educação no Brasil.

Dentro dessa perspectiva de colaboração, pensar o papel institucional das secretarias municipais de educação, na promoção do debate da BNCC, torna-se pertinente por ressignificar suas ações e direcioná-las para uma ampliação do seu estatuto democrático, ou seja, passar de um papel meramente fiscalizador e instrumental para uma condição de agente promotor e mediador dos saberes da Educação Física.

Uma experiência de construção no município do Natal precede o debate da BNCC, que culminou com a elaboração dos Referenciais Curriculares para a Educação Física do Ensino Fundamental no ano de $2008^{6}$. Tal preceito insere e projeta a institucionalidade das secretarias para além de um exercício instrumental, trazendo atribuições que horizontalizam as relações na construção do conhecimento para a área.

Em novembro de 2015, foi realizado o Fórum de Discussão sobre a BNCC - Educação Física. Esta ação, pensada a partir da iniciativa dos professores responsáveis pela formação continuada em Educação Física do Município do Natal/RN, buscou atender as demandas das reflexões sobre a Educação Física brasileira em resposta às indagações e propostas da $2^{\text {a }}$ Conferência Nacional pela Educação - CONAE, que desencadeou o processo de mobilização para a construção do documento que servirá à BNCC (BRASIL, 2016).

Após o lançamento do Portal da Base Nacional Comum Curricular e a abertura do processo de elaboração da Base, buscamos desenvolver a divulgação, discussão e construção coletiva entre os segmentos sociais e educacionais interessados nesta elaboração no tocante a organização do conhecimento da Educação Física.

Assim, o Fórum objetivou realizar uma reflexão crítica sobre a primeira versão da BNCC, além de trazer o professor como colaborador desta construção democrática, acreditando que este traz saberes de sua experiência cotidiana, que em conjunto com os

6 Referenciais Curriculares para a Educação Física do Ensino Fundamental (Natal, 2008) - Foi construído ao longo de um processo de debate, cujo início se deu em 2006, suas proposições não encerravam em direcionamentos definitivos para a prática pedagógica dos professores de Educação Física, mas sim, trouxeram um olhar para o componente, enquanto elemento norteador para o processo contínuo de aperfeiçoamento das propostas curriculares presentes nos Projetos Políticos Pedagógicos desenvolvidos na instituições de ensino do município. É importante destacar que com a criação do documento, que emergiu de demandas internas dos professores de Educação Física, passamos a ter um movimento onde a construção do conhecimento partia de demandas reais das escolas. Passávamos de uma condição passiva de apropriação do conhecimento para uma construção dos saberes que dialogavam com as realidades que emergiam das escolas e com as tendências teóricas práticas que eram consideradas importantes para fundamentar este documento produzido coletivamente. (http://natal. rn.gov.br/sme/). 
saberes acadêmicos, possam produzir avanços para a Educação Física enquanto componente curricular. Nesse sentido, articulamos com o corpo docente do Departamento de Educação Física da Universidade Federal do Rio Grande do Norte, estudantes do PIBID, conjuntamente com os professores das redes estadual e municipal, além dos monitores do Programa Mais Educação, o debate deste Fórum, que ocorreu nos dias 16 e 30 de novembro de 2015 e será apresentado a partir deste Relato de Experiência.

Metodologicamente, iniciamos com a explanação sobre a Educação Física no contexto da BNCC e, em seguida, os participantes apresentaram seus questionamentos sobre o tema.

Continuamos a discussão através de Grupos de Trabalho (GT), os quais foram pensados de acordo com a organização das manifestações da cultura corporal de movimento trazidas pelo documento: Brincadeiras e Jogos; Esportes; Lutas, Exercícios Físicos e Práticas Corporais de Aventura; Ginásticas e Práticas Corporais Rítmicas; Ensino Médio. Por fim, os participantes apresentaram as críticas discutidas em cada grupo, apontando possíveis contribuições que foram registradas e documentadas e, em seguida, socializadas nas escolas para que fossem inseridas no portal da Base. Acreditamos que este foi um momento enriquecedor para a Educação Física escolar deste município.

A seguir, contextualizaremos a Educação Física na BNCC, a partir de um breve percurso histórico, para que possamos compreender como se deu o processo de inserção deste componente curricular na mesma.

\section{A Educação Física no contexto da BNCC}

As necessidades da Base Nacional Comum Curricular estão postas desde a constituição de 1988 em sua parte que trata da educação, mas somente com a aprovação da Lei de Diretrizes e Bases da Educação Nacional (LDBEN), Lei 9.394, de 20 de dezembro de 1996, ela é regulamentada. Em seu artigo 26, aponta uma base nacional comum para a Educação Básica, em cujo currículo deve estar presente a parte diversificada atendendo as características regionais da sociedade. No mesmo sentido, em 1997 são formulados os Parâmetros Curriculares Nacionais ( $\mathrm{PCN})$, que vieram como referências às discussões pedagógicas auxiliando as escolas na elaboração dos seus currículos.

Em 2010, na CONAE, especialistas se uniram para debater a importância da BNCC, como parte de um Plano Nacional de Educação (PNE). Neste mesmo ano, foram definidas as Diretrizes Curriculares Nacionais Gerais para a Educação Básica (DCN), compostas por leis que definiram metas e objetivos a serem buscadas em cada área do conhecimento.

O PNE, regulamentado pela Lei $n^{\circ} 13.005$, de 25 de junho de 2014 faz em quatro de suas vinte metas, referência a BNCC. Dentre elas, a Meta 2 que trata da universalização do ensino fundamental para toda a população de 6 a 14 anos, e determina entre suas estratégias que

O Ministério da Educação, em articulação e colaboração com os Estados, o Distrito Federal e os Municípios, deverá, até o final do $2^{\circ}$ (segundo) ano de vigência 
deste PNE, elaborar e encaminhar ao Conselho Nacional de Educação, precedida de consulta pública nacional, proposta de direitos e objetivos de aprendizagem e desenvolvimento para os (as) alunos (as) do ensino fundamental (BRASIL, 2014).

Neste sentido, compreendemos que a BNCC servirá como ferramenta na orientação da construção do currículo das escolas, esclarecendo para o professor quais os conhecimentos fundamentais que os educandos deverão ter acesso em cada ano de escolaridade. Deste modo, a BNCC apresenta-se estruturada por Áreas de conhecimento (Linguagens, Matemática, Ciências da Natureza, Ciências Humanas e Ensino Religioso). Dentro destas áreas, encontram-se os componentes curriculares, sendo que a Educação Física se encontra na área de Linguagens.

Acreditamos na importância desta organização apresentada pela Base no que tange aos conhecimentos trazidos por cada componente, em particular a Educação Física, que muitas vezes negligencia o amplo repertório dos seus conteúdos em benefício de outros. Poderíamos indagar, por exemplo: quantos alunos passaram pela escola sem ter acesso ao conteúdo dança? Compreende-se que esta problemática provoca uma desarticulação do professor no tocante à seleção dos conteúdos, que muitas vezes, seleciona estes saberes apenas por afinidade.

Histórica e culturalmente, a Educação Física se apresenta como uma área exclusivamente prática, tendo como ação e intervenção o "saber fazer". Esse entendimento é fruto de uma construção histórica, em que no início do século XIX,

[...] em função da necessidade de sistematizar a ginástica na escola, surgem os métodos ginásticos. [...] propostas que procuravam valorizar a imagem da ginástica na escola e, assim, acabaram por fornecer elementos para o aprimoramento físico dos indivíduos. Os métodos ginásticos procuravam capacitar os indivíduos no sentido de contribuir com a indústria nascente e com a prosperidade nação (DARIDO, 2008, p.01-02).

Neste período, não havia uma organização curricular direcionada para o contexto escolar que atendesse aos alunos a partir do seu nível de escolaridade, faixa etária, maturação física, afetiva e cognitiva. O que acontecia era uma reprodução dos métodos ginásticos, onde todos os alunos tinham que realizar as atividades físicas propostas pelo professor, independentemente das suas condições e limitações físicas.

Contudo, no período de 1980, devido a um cenário político que não atendia mais às necessidades educacionais da época, o modelo de esporte de alto rendimento apresentado nas escolas foi criticado e, na busca de alternativas, surgiram novas formas de pensar a educação física na escola. Naquele momento, a Educação Física deu início à mudanças teóricas e metodológicas no seu ensino escolar em todo o Brasil, partindo de reflexões e questionamentos sobre o seu papel.

Nesse período, algumas mudanças foram configurando-se na Educação Física, causando muitos embates na área: debates formaram-se, questionando a realidade da Educação Física daquele período. Contribuiu para isso, também, a volta de professores que 
fizeram doutorado no exterior trazendo novas ideias, criação de cursos de pós-graduação, a realização de congressos, aumento do número de publicações e seminários na área, além de uma mudança no conteúdo das publicações, antes voltadas para áreas técnicas e biológicas comuns naquele período. Temas como esporte, treinamento, desempenho e preparação física, por exemplo, foram gradativamente dividindo espaço com publicações voltadas para áreas das ciências sociais, com viés pedagógico, da psicologia, pedagogia e sociologia, dentre outros (DAOLIO, 1998).

Essas propostas foram orientadas por princípios políticos, filosóficos, culturais, históricos e sociológicos, pautados em refletir sobre o homem, sua identidade, os valores da educação e o papel social da escola. Assim,

Em oposição à vertente mais tecnicista, esportiva e biológica surgem novos movimentos na Educação Física escolar a partir, especialmente, do final da década de 1970, inspirados no novo momento histórico-social por que passou o país, a Educação de uma maneira geral e a Educação Física especificamente (MATTHIESEN et al., 2008, p. 03).

Como resultado dessas críticas, surgiram algumas importantes propostas pedagógicas que, enunciadas como concepções ou abordagens, apontaram para a possibilidade de construção da organização do conhecimento que pretendia mudar os objetivos e as ações dos professores de Educação Física nas escolas brasileiras.

No ano de 1996, é aprovada a nova Lei de Diretrizes e Bases da Educação (Lei no 9394/96) que configura a Educação Física escolar como uma disciplina de igual importância às demais que compõem o currículo. No art. 26, parágrafo $3^{\circ}$, da LDB em vigor, "a educação física, integrada a proposta pedagógica da escola, é componente curricular obrigatório da Educação Básica, ajustando-se as faixas etárias e as condições da população escolar, sendo facultativa nos cursos noturnos" (BRASIL, 1996). A Lei no 10793/20037 alterou a redação do art. $26, \S 3^{\circ}$ tornando a Educação Física, integrada à proposta pedagógica da escola, componente curricular obrigatório da educação básica, sendo sua prática facultativa ao aluno que cumpra jornada de trabalho igual ou superior a seis horas; maior de trinta anos de idade; que estiver prestando serviço militar inicial ou que, em situação similar, estiver obrigado à prática da educação física; amparado pelo Decreto-Lei no 1.044, de 21 de outubro de 1969, que tenha prole e não mais facultativos apenas aos cursos noturnos.

A Educação Física passou de uma mera atividade desenvolvida na escola ao status de componente curricular obrigatório vinculado ao projeto pedagógico da escola. Dessa forma, se faz necessária a discussão dos saberes que serão compartilhados e ensinados, tendo a responsabilidade político-social a partir da sua prática pedagógica.

Paralelo a esse novo posicionamento da Educação Física, o Governo Federal, a partir do Ministério da Educação e do Desporto, lança um documento denominado

7 Em 22 de setembro de 2016, o presidente Michel Temer assinou e encaminhou, ao Congresso Nacional, uma Medida Provisória (MP 746) para reestruturação do ensino médio que, se aplicada, ampliará o retrocesso iniciado na Lei ${ }^{\circ}$ 10793/2003 o que fragilizaria a Educação Física como componente curricular por torná-lo facultativo em uma parte do ensino médio. 
Parâmetros Curriculares Nacionais - PCN (BRASIL, 1998), que contemplou todas as disciplinas obrigatórias do ensino fundamental e ensino médio e foi distribuído nas escolas públicas brasileiras. Os PCN objetivam auxiliar os professores no seu fazer pedagógico e para a Educação Física expõem que esta é

[...] a área de conhecimento que introduz e integra os alunos na cultura corporal do movimento, com finalidades de lazer, de expressão de sentimentos, afetos e emoções, de manutenção e melhoria da saúde. Para tanto, rompe com o tratamento tradicional dos conteúdos que favorecem os alunos que já têm aptidões, adotando como eixo estrutural da ação pedagógica o princípio da inclusão, apontando para uma perspectiva metodológica de ensino e aprendizagem que busca o desenvolvimento da autonomia, da cooperação, da participação social e da afirmação de valores e princípios democráticos. Neste sentido, busca garantir a todos a possibilidade de usufruir de jogos, esportes, danças, lutas e ginástica em benefício do exercício crítico da cidadania (p.62).

Nessa nova ordem institucional, foi exigido dos professores de Educação Física pensar e agir de outra forma na escola, já que a área foi concebida nas mesmas condições dos demais componentes curriculares, nos quais a organização dos seus aspectos didáticos a consolida na educação escolarizada. Essa nova situação da disciplina como componente curricular para os profissionais exigiu destes a participação efetiva na concepção do projeto pedagógico, já que suas práticas devem ser orientadas pelas diretrizes desse documento escolar.

Os PCN foram criados para auxiliar as escolas a desenvolver os seus currículos e ajudar na execução de seus trabalhos. Em relação à Educação Física, o documento traz uma visão bem aproximada com os caminhos apontados pelo Coletivo de Autores (1992), no que se refere ao rompimento da visão tecnicista a qual a Educação Física era anteriormente impregnada. Sugere a integração da cultura corporal do movimento, com finalidades de lazer, de expressão de sentimentos, afetos e emoções, de manutenção e melhoria da saúde. Organiza os conhecimentos da Educação Física em três blocos de conteúdos: conhecimentos sobre o corpo; esportes, jogos, lutas, ginásticas; e atividades rítmicas e expressivas.

Outro autor que já apontava para a necessidade de uma organização desses conteúdos é Kunz (2003), que sugeriu um "programa mínimo", deixando claro que o mesmo deveria ser flexível, e viria a pôr um fim no que ele chama de "bagunça interna" na Educação Física como disciplina/atividade escolar, causada pela inexistência de um programa de conteúdos numa hierarquia de complexidade. Em relação a essa preocupação ele afirma que

[...] o professor decide, de acordo com alguns fatores (entre eles o seu bom e mau humor), o que ensinar. Por exemplo, ele pode optar por conteúdos exatamente iguais para a quinta série do primeiro grau e a segunda série do segundo grau, se quiser (e muitas vezes acontece). Da mesma forma, o grau de complexidade no ensino pode ser exatamente igual, para os dois momentos. O mesmo não acontece, por exemplo, numa aula de matemática, geografia ou português "o que é que vamos ter hoje, professor?" Como acontece, constantemente, numa aula de Educação Física (p. 150 - 151). 
Várias tentativas surgiram em busca de organizar os conteúdos da Educação Física. Trazemos duas propostas bem diversificadas para que possamos compreender que precisamos de um documento que embase legitimamente a organização deste componente curricular, para que uma mesma linguagem possa ser falada entre os professores da área quando se trata da organização dos conteúdos da Educação Física. Não na intenção de reduzir as discussões, mas que a Educação Física, enquanto componente curricular supere essa "bagunça" apontada por Kunz.

A primeira proposta que trazemos é a de Freire \& Scaglia (2009) que apresentam uma sugestão de organização curricular desde a Educação Infantil até os anos finais do Ensino Fundamental, a partir de 22 temas $^{8}$, que correspondem aos conteúdos, e subtemas subdivididos em seis categorias, da seguinte forma: motores, sociais, afetivos, intelectuais, perceptivos e simbólicos. Os autores trazem um modelo de sistematização desses conteúdos no intuito de facilitar o planejamento dos professores de Educação Física.

Palma, Oliveira e Palma (2010) trouxeram outra proposta de organização curricular, também objetivando subsidiar a prática dos professores de Educação Física, estabelecendo conteúdos compatíveis com os níveis escolares, com uma visão que consideram ser mais ampla que os PCN, apontando o movimento humano culturalmente construído como objeto de estudo da Educação Física, portanto, como referência na seleção dos conteúdos: a corporeidade, os jogos, os esportes, a expressão, o ritmo e a saúde. Os autores (idem, 2010, p.58) afirmam que: "o que não pode mais aceitar é a desorganização e o deixar fazer, que toma conta das ações cotidianas de muitas aulas de Educação Física nas escolas".

A BNCC vem trazer de forma legítima a organização dos conteúdos, definindo com clareza os objetivos de aprendizagem, os quais os educandos devem ter o direito de aprender, independente da escola que frequente. Somos conscientes de que é preciso algo muito mais amplo para oportunizar uma educação de forma igualitária para todos, mas consideramos a BNCC um passo importante nesse sentido.

A Educação Física encontra-se dentro da área de Linguagens que reúne os quatro componentes curriculares: Língua Portuguesa, Língua Estrangeira Moderna, Arte e Educação Física. Na perspectiva do documento, esses componentes articulam-se na medida em que envolvem experiências de criação, de produção e de fruição de linguagens.

Concebida como forma de ação e interação no mundo e como processo de construção de sentidos, a linguagem é, portanto, o elo integrador da área. A utilização do termo linguagens, no plural, aponta para a abrangência do aprendizado na área, que recobre não apenas a linguagem verbal, mas as linguagens musical, visual e corporal (BRASIL, 2015).

A Educação Física vem sendo discutida como área de linguagem há algum tempo. O Coletivo de Autores (1992) trouxe avanços sobre essa discussão, quando traz a "expressão corporal como linguagem" e o reconhecimento do movimento como "linguagem

8 Sensibilização Corporal, Jogos Simbólicos, Jogos de Construção, Jogos de Regras, Rodas Cantadas, Brincadeiras Populares, Ginástica Geral, Dança Folclórica, Lutas Simples, Jogos Pré-desportivos, Atividades de Fundamentação do Esporte, Atividades de Percepção Corporal, Relaxamentos, Alongamentos, Lutas, Ginásticas, Danças, Atividades Alternativas, Esportes individuais, Esportes com Raquetes, Esporte sobre Rodas e Esportes com Bolas. 
corpórea", aproximando o componente curricular Educação Física do corpo como linguagem.

Desta forma, a Educação Física não faz parte das Ciências Naturais. Isso significa que avançamos no que se refere ao lugar que ocupamos. Fazer parte da área de Linguagens é confirmar que temos um corpo que ultrapassa o orgânico. Darido (2008, p.132) afirma que "antes mesmo de comunicarem-se através das palavras, os seres humanos já se comunicavam por meio do movimento e do corpo, que sente, se expressa e se movimenta. O corpo fala". A autora compreende que se esse corpo fala, ele deve ser passível de leitura dos professores, principalmente pelos professores de Educação Física já que através dela o corpo deveria ser conhecido.

A Educação Física, no contexto atual, quando inserida na área das Linguagens, tenta romper a visão biologicista que durante tanto tempo esteve enraizada, e traz a visão de um corpo que não nega o orgânico, mas que, mais do que nunca, valoriza a cultura na qual encontra-se inserido, trazendo a cultura de movimento como seu objeto de estudo. Mendes e Nóbrega (2009, p. 03) compreendem que

\begin{abstract}
A cultura de movimento, ao envolver a relação entre corpo, natureza e cultura, configura-se como um conhecimento que vai sendo construído e reconstruído ao longo de nossas vidas e da história. Um conhecimento marcado pela linguagem sensível, que emerge do corpo e é revelada no movimento que é gesto, abarcando os aspectos bioculturais, sociais e históricos, não se resumindo às manifestações de jogos, danças, esportes, ginásticas ou lutas, mas abrangendo as diversas maneiras como o ser humano faz uso do ser corpo, ou seja, como cria e vivencia as técnicas corporais.
\end{abstract}

Nesse sentido, entendemos a importância que a Educação Física tem como prática pedagógica, trazendo os saberes relacionados a essas manifestações, incentivando os educandos a conhecer e compreendendo as suas singularidades de forma crítica. Contudo, os documentos oficiais e as propostas apresentadas não propuseram uma sequência didática e os direitos de aprendizagem dos alunos de acordo com o ano de escolaridade, fato que já é apontado pela BNCC.

\title{
Dialogando sobre a BNCC na formação continuada
}

Após a abertura da consulta pública da primeira versão da base nacional comum curricular, os educadores de todo país foram convocados a conhecer e contribuir na elaboração do mesmo. Nesse sentido, uma proposta de cronograma, em âmbito estadual, foi estabelecida para que o estado do Rio Grande do Norte e seus municípios pudessem se organizar, no intuito de mobilizar seus educadores para uma discussão do documento apresentado, onde os mesmos fossem estimulados não somente a conhecer, mas também a analisar e contribuir com a construção deste documento.

Seguindo as orientações, nós, assessores pedagógicos da Secretaria Municipal de Educação do Natal, nos reunimos com a Secretária de Educação do Município, juntamente 
com a comissão formada para a discussão das ações institucionais, decidindo, entre outras propostas, que a BNCC deveria ser discutida na formação continuada de todos os componentes curriculares.

O município do Natal oferece, de forma sistematizada, formação continuada a todos os professores em exercício na rede, na qual os professores de Educação Física participam quinzenalmente. O setor responsável por organizar e executar estas formações - Setor de Ações e Projetos/Departamento de Ensino Fundamental - é constituído por professores de todas as áreas.

Nós, assessores pedagógicos da área de Educação Física, acreditamos que este seria um momento ímpar, visto que este componente particularmente, talvez mais do que os outros, apresenta lacunas referentes à estrutura curricular e, apesar de normatizada pela Lei de Diretrizes e Bases n 9.394/96 (LDB), é preciso avançar no sentido desta ser reconhecida socialmente pela comunidade escolar.

O trabalho colaborativo no debate da BNCC revelou a importância de estabelecermos sistematicamente canais de dialogo com o professor, por ser este detentor de um saber, de uma experiência, que não pode deixar de estar presente no processo de construção democrática. Dessa forma, a formação continuada promovida pela Secretaria constitui-se em locus privilegiado do encontro e socialização do conhecimento da Educação Física escolar.

Nesse sentido, articulamos com o Departamento de Educação Física da Universidade Federal do Rio Grande do Norte, através do seu corpo docente, um encontro para discutirmos a temática da BNCC que se formatou no Fórum de Discussão da Base Nacional Comum Curricular em Educação Física, cujos objetivos foram de conhecermos o documento preliminar, assim como de contribuirmos com críticas e sugestões a respeito dele. A ação envolveu professores da UFRN, Professores de Educação Física da Rede Municipal de Natal, estudantes do PIBID e monitores do Programa Mais Educação (Macrocampo Esporte e Lazer).

O Encontro ocorreu nos dias 16 e 30 de novembro do ano de 2015, o primeiro no auditório do Departamento de Educação Física da UFRN e o segundo no Centro Municipal de Referência em Educação Aluísio Alves (CEMURE). A abertura foi proferida pelo professor Dr. José Pereira de Melo, "um diálogo" com os professores sobre a importância deste documento para a área. Em seguida, a professora mestranda Wanessa Cristina Rodrigues apresentou a palestra "A apresentação da Base Nacional Comum Curricular - Como podemos contribuir?", expondo a proposta da mesma e orientando os participantes sobre o cadastro e a inserção das contribuições na construção da BNCC. Foi apresentada também a homepage em que se encontrava disponível a versão preliminar do referido documento, exposta à contribuições de toda população de modo geral.

Outra palestra intitulada "Reflexão sobre a Educação Física no contexto da BNCC" foi ministrada pelo professor mestrando José Ribamar Ferreira Júnior, explanando a forma como a Educação Física se apresenta na BNCC. No documento, a mesma está inserida na área das Linguagens, trazendo como a referência central para a estruturação dos conhecimentos a prática corporal, entendida como uma forma de relação do ser humano com o mundo e de interação com os outros sujeitos, compreendendo que a origem e a dinâmica de 
transformação das representações e práticas sociais constituem a cultura corporal de movimento. Esse entendimento envolve os objetivos de aprendizagem específicos da Educação Física, que foram organizados em cinco ciclos, com base nas seguintes manifestações da cultura corporal de movimento: brincadeiras e jogos; esportes; exercícios físicos; ginásticas; lutas; práticas corporais alternativas; práticas corporais de aventura; práticas corporais rítmicas.

Após a apresentação, foi aberto um momento para o debate, quando os professores trouxeram seus questionamentos sobre o tema. A priori, alguns trouxeram à tona a ideia que o documento poderia vir a "engessar" o componente curricular, ou seja, determinar o que os professores deveriam ministrar em suas aulas, tirando-lhes a autonomia. No entanto, durante a discussão houve o consenso de que a BNCC busca promover uma equidade de acesso dos alunos aos conteúdos, mantendo a liberdade metodológica do professor. No tocante aos conteúdos, a singularidade permanecerá, pois será garantida pelo currículo de cada município e estado, visto que este não se resume à BNCC. Este deve englobar sua parte diversificada, o que traz o currículo da rede e o que traz a Base.

Em seguida, continuamos a discussão, porém, em grupos de trabalho, os quais foram pensados de acordo com a organização das manifestações da cultura corporal de movimento trazido pelo documento. Os participantes escolhiam por afinidade em que pudessem trazer mais contribuições: GT 01 - Brincadeiras e jogos; GT 02 - Esportes; GT 03 - Lutas, exercícios físicos e práticas corporais de aventura; GT 04 - Ginásticas e práticas corporais rítmicas; GT 05 - Ensino Médio 9 .

Cada grupo de estudo contou com a colaboração de dois coordenadores, um professor da Rede Municipal do Natal e um professor representante da Universidade Federal do Rio Grande do Norte. Os grupos tinham como finalidade discutir os objetivos gerais da Educação Física e realizar a leitura de todos os objetivos específicos propostos por ciclo/manifestação cultural, a fim de avaliá-los. Estes eram avaliados individualmente pelo grupo e quando a maioria discordava, o código dele era registrado e as sugestões eram anotadas no instrumento de avaliação para que fossem posteriormente inseridas como contribuições no portal da BNCC. Após esse momento, retornarmos à discussão coletiva, ocasião em que as sugestões foram compartilhadas, sendo acordado que as conclusões seriam consideradas no segundo dia do Fórum.

No segundo encontro, apenas os professores de Educação Física da Rede Municipal de Educação do Natal participaram, permanecendo os mesmos grupos para as discussões. Finalizamos com a socialização das contribuições sugeridas e as mesmas foram registradas em relatório. Essas contribuições que serão apresentadas a seguir, foram encaminhadas a todas as unidades de ensino da rede municipal do Natal, para que as mesmas fossem inseridas no portal da BNCC.

9 Este último foi pensado na possibilidade de que representantes deste nível de ensino estivessem presente, já que seria necessária uma discussão mais específica; porém, o mesmo foi extinto por falta de representação. 
Resultados das contribuições da Rede Municipal de Natal

No momento das reuniões com os grupos, foi debatido o texto introdutório do componente curricular Educação Física na educação básica, os objetivos gerais e os objetivos de aprendizagem específicos por prática corporal em ciclos. Para os professores, as informações destes itens apresentam linguagem clara, permitindo que sejam compreendidos pelos participantes da discussão pública, assim como as ideias são pertinentes e relevantes para o componente curricular, tendo em vista o seu papel na educação.

Referente aos objetivos de aprendizagem, os professores sentiram a ausência do "Conhecimento sobre o corpo", conteúdo que estava presente nos PCN. Eles destacam que este é um conteúdo importante, visto que ele trazia uma reflexão sobre o corpo, suas características e peculiaridades. Alguns defenderam que este teria sido diluído nas demais manifestações culturais, contudo a maioria acredita que ele deveria estar explícito no documento.

Outra situação bastante questionada foi a ausência do conteúdo Lutas no primeiro ciclo $\left(1^{\circ}, 2^{\circ}\right.$ e $3^{\circ}$ ano do Ensino Fundamental). A compreensão dos professores é que não há nada que impeça os alunos do primeiro ciclo de ter acesso a esse conteúdo, assim como não foi compreendido porque que o mesmo não está inserido no quinto ciclo $\left(1^{\circ}, 2^{\circ}\right.$ e $3^{\circ}$ ano do Ensino Médio). Após uma ampla discussão, o grupo chegou à conclusão de que os elementos deste conteúdo podem ser explorados no primeiro ciclo através dos Jogos e Brincadeiras; já no $5^{\circ}$ ciclo, até pode estar inserido entre os Esportes, mas não explica o fato dele estar ausente, pois nem toda Luta é Esporte. Verificamos que na segunda versão do documento, o conteúdo Lutas continua sendo contemplado do segundo ao quarto ciclo apenas ( $4^{\circ}$ ao $7^{\circ}$ ano do Ensino Fundamental).

A utilização do termo "Ginástica Geral" para definir o conteúdo Ginástica foi outra questão bastante polêmica. Os professores afirmam que a nomenclatura "Ginástica Geral" é utilizada para definir o conteúdo de Ginásticas, porém a ginástica geral está dentro da ginástica, e a forma que se apresenta no documento parece que uma substitui a outra. Na segunda versão, podemos verificar que o termo já foi trocado e a nomenclatura "Ginásticas" prevaleceu. Ainda em relação a este conteúdo, houve uma crítica por não estar contemplado nos $4^{\circ}$ e $5^{\circ}$ ciclos, sendo também revisto na segunda versão do documento, pois a Ginástica passa a ser conteúdo de todos os ciclos na atual versão da BNCC, assim como os Esportes e as Danças.

Em relação ao conteúdo Esportes, a classificação utilizada - Esportes de Precisão, Esportes de Rede ou Parede, Esportes de Rebote e Esportes de Invasão - é algo novo para a maioria dos professores, por ser uma maneira recente de caracterizar os esportes. A crítica prevaleceu sobre o $4^{\circ}$ ciclo, onde em diversos objetivos aparece o termo "esporte escolhido" para ser trabalhado com os alunos, não ficando claro quais os critérios e por quem esse esporte será escolhido. De repente, isso pode incentivar o que já acontece nas escolas, em que apenas os esportes considerados mais populares são trabalhados - como, por exemplo, o Futsal e o Vôlei. 
No documento atual, observamos que a classificação dos esportes aparece detalhada ao lado dos objetivos dos ciclos, o que facilita o entendimento para aqueles professores que ainda não tiveram acesso a esta compreensão. Em relação ao termo "esporte escolhido", o documento traz de forma mais esclarecida como deve ser realizada esta escolha, sendo possível observar essa mudança em um dos objetivos "EF06EF02 - Praticar uma ou mais modalidades esportivas, escolhidas pelo coletivo da escola, usando habilidades técnico-táticas básicas" (BRASIL, 2016, p.384).

Na primeira versão do documento, os Exercícios Físicos foram trazidos na modalidade de conteúdos, o que gerou insatisfação na maioria dos professores, que desta forma poderiam retroceder à visão tecnicista da Educação Física. Já na versão atual do documento os mesmos foram inseridos no conteúdo de Ginásticas. Essa inserção é explicada através de uma nota ao lado do conteúdo Ginásticas do $3^{\circ}$ ciclo.

No $3^{\circ}$ ciclo dos anos finais do Ensino Fundamental, conclui-se o tratamento pedagógico das ginásticas de demonstração ao focalizar a construção de apresentações e composições temáticas. No mesmo ciclo, se inicia o trabalho com a ginástica de condicionamento físico, privilegiando os conhecimentos envolvidos na prática sistemática de exercícios físicos. No $4^{\circ}$ ciclo, o estudo dessa manifestação gímnica ganha complexidade com a tematização dos programas de exercícios físicos (BRASIL, 2016).

Através deste recorte, fica implícita a concretização da valorização da técnica, no momento em que o tratamento pedagógico das ginásticas deve estacionar no $3^{\circ}$ ciclo e no final do mesmo o documento sugere que deva ser trabalhado o condicionamento físico, através dos exercícios físicos, o que não condiz com o objeto de estudo da Educação Física Escolar ${ }^{10}$, que deveria ser a cultura corporal de movimento. O condicionamento físico deve ficar a cargo da Educação Física que está fora da escola.

Uma mudança significativa na segunda versão da BNCC foi o retorno do conteúdo Danças para a Educação Física. O mesmo estava mais presente na área das Artes, e aparecia timidamente no conteúdo da primeira versão, na qual estava inserido junto às Práticas Corporais Rítmicas. Na segunda versão, a BNCC considera que “Diferentemente de outras práticas corporais rítmico-expressivas, estas se desenvolvem em codificações particulares, historicamente constituídas, que permitem identificar movimentos e ritmos musicais peculiares, associados a cada uma delas" (BRASIL, 2016, p.248). Nesse sentido, as Danças voltam a fazer parte dos conteúdos da Educação Física e o termo Práticas Corporais Rítmicas desaparece desta versão.

\section{CONSIDERAÇÕES FINAIS}

Como podemos perceber, houve mudanças significativas desde a primeira versão até a segunda versão (atual) da BNCC. Entendemos que isso se deu porque a sociedade encarou o desafio de participar da construção de um documento tão importante para a 
educação do nosso país. Foram exatamente 12.226.510 (doze milhões duzentos e vinte e seis mil quinhentos e dez) contribuições recebidas ao documento preliminar de forma geral, das quais 4.824 (quatro mil oitocentos e vinte e quatro) voltadas para o componente curricular Educação Física, sendo 4.449 (quatro mil quatrocentos e quarenta e nove) contribuições voltadas aos objetivos gerais deste componente na Educação Básica e 4.514 (quatro mil quinhentos e quatorze) voltadas aos objetivos de aprendizagem específicos por prática corporal em ciclos. A soma das contribuições específicas ao componente curricular Educação Física totaliza 13.787 (treze mil setecentos e oitenta e sete).

Em todo país, mais de 35 mil escolas enviaram suas sugestões a partir de debates que elas promoveram com seus professores, alunos e pais, em seus territórios. Nós nos orgulhamos de fazer parte desta estatística. Comparadas ao número total de contribuições, aquelas realizadas à Educação Física aparecem de forma tímida. No entanto, acreditamos que estas tenham sido relevantes quando percebemos as mudanças da primeira versão para a segunda (atual). Consideramos que algumas se apresentam como avanços, já outras precisariam ser revistas.

Desde que o governo atual assumiu, muitas incertezas cercam o campo educacional no cenário nacional, uma delas é a publicação da BNCC. Sequer temos a certeza de que esta ocorrerá. Os Seminários Estaduais voltados a debater a segunda versão da BNCC e sistematizar as contribuições através de relatórios para entregar ao Ministério da Educação (MEC) ocorreram até o final de agosto. Desde então, não existe disponível no portal da base um novo calendário que indique as próximas atividades.

Mesmo diante dessas incertezas, pretendemos avançar no que se refere à discussão da BNCC através dos nossos encontros quinzenais da formação continuada dos professores de Educação Física da rede municipal do Natal, pois, ela apresenta um norte que pretendemos utilizar na atualização da proposta curricular da rede municipal do nosso município. Além disso, o professor precisa conhecê-la profundamente, pois sendo aprovada, é a partir desta que os projetos políticos pedagógicos e os currículos das escolas deverão ser atualizados.

Apesar de o documento ter muitas questões a serem refletidas e criticadas, consideramos que a BNCC se apresenta como um caminho, que traz possibilidades de uma equidade quando nos referimos ao acesso dos alunos aos conteúdos. A Educação Física especificamente precisa urgentemente de uma organização curricular, pois diferente de diversas propostas que apontam direções neste sentido, a Base Nacional Comum Curricular deverá ser implantada como lei e precisará ser cumprida.

\section{REFERÊNCIAS}

BRASIL. Base Nacional Comum Curricular: documento preliminar. Disponível em: <http:// basenacionalcomum.mec.gov.br/\#/site/inicio > . Acesso em: 15 nov. 2015. . Lei de Diretrizes e Bases para a Educação Nacional. Brasília: MEC, 1996. . Lei no 13.005, de 25 de junho de 2014. Brasília: MEC, 1996. Disponível em: http:// 
www.planalto.gov.br/CCIVIL_03/_Ato2011-2014/2014/Lei/L13005.htm . Acesso em: 20 maio 2016.

. Plano Nacional de Educação PNE 2014-2024: Linha de Base. - Brasília, DF: Inep, 2014. Disponível em: < http://pne.mec.gov.br/images/pdf/pne_conhecendo_20_metas. pdf $>$ Acesso em: 20 maio 2016.

. Secretaria de Educação Fundamental. Parâmetros Curriculares Nacionais: Educação

Física. Brasília: MEC/SEF, 1997.

. Senado Federal. Constituição da República Federativa do Brasil. Brasília, 2008.

.Base Nacional Comum Curricular: documento atual. Disponível em: < http:// basenacionalcomum.mec.gov.br/\#/site/inicio > . Acesso em: 20 maio 2016.

COLETIVO DE AUTORES. Metodologia do Ensino de Educação Física. São Paulo: Cortez, 1992.

DAOLIO, Jocimar. Educação física brasileira: autores e atores da década de 1980. Papirus Editora, 1998.

DARIDO, Suraya Cristina. Educação Física na escola: questões e reflexões. Rio de Janeiro, Guanabara Koogan, 2008.

FREIRE, João B. SCAGLIA, Alcides J. Educação como prática corporal. 2 ed. São Paulo: Scipione, 2009.

KUNZ, Elenor. Transformação Didático-pedagógica do esporte. 5ed. Ijuí: Ed.Unijuí, 2003. MATTHIESEN, Sara Quenzer et al. Linguagem, corpo e educação física. Revista Mackenzie de Educação Física e Esporte, v. 7, n. 2, 2008.

MENDES, Maria Isabel B. S.; NÓBREGA, Terezinha Petrúcia. Cultura De Movimento: Reflexões a partir da Relação entre Corpo, Natureza e Cultura. Pensar a Prática, Goiânia, v. 12, n. 2, ago. 2009. ISSN 1980-6183. Disponível em: < https://revistas.ufg.br/fef/ article/view/6135/4981 > . Acesso em: 20 jun. 2016.

NATAL, Secretaria Municipal de Educação. Referenciais Curriculares para os anos iniciais e finais do ensino fundamental: educação física. Secretaria Municipal de Educação do Natal. Margarete Ferreira do Vale Sousa e Maria Tereza de Moraes (org.) - NATAL, RN: Secretaria Municipal de Educação, 2008. Disponível em: < http://natal.rn.gov.br/ sme/>. Acesso em: 20 jun. 2016

PALMA, Ângela Pereira T. V.; OLIVEIRA, Amauri Aparecido B.; PALMA, José Augusto V. Educação Física e a Organização Curricular: Educação Infantil, Ensino Fundamental, Ensino Médio. 2 ed. Londrina. PR: Ed. UEL, 2010. 
DISCUSSING THE BNCC (COMMON CURRICULAR NATIONAL BASIS) IN THE CONTINUING EDUCATION OF PHYSICAL EDUCATION TEACHERS: an experience report - Natal/RN

\begin{abstract}
After the launch of the portal BNCC (Common Curricular National Basis)and the consequent possibility of online public input, a schedule was proposed so each Brazilian state and its respective municipalities could discuss the document among its educators and make timely contributions. In order to do so, we teachers who work with continuing education for Physical Education teachers in the Natal municipal department of education proposed the discussion forum on the Common Curriculum National Basis. Therefore, the forum aimed to carry out a critical reflection on the BNCC and bring the teacher as developer of this democratic construction. The forum was discussed among all these groups: faculty of physical education department of the Federal University of Rio Grande do Norte. This discussion was held on November 2015, and will be presented through this report.
\end{abstract}

Keywords: National Basis; Continuing Education; School Physical Education.

\title{
LA BNCC EN LA DISCUSIÓN SOBRE FORMACIÓN CONTINUA DE LOS PROFESORES DE EDUCACIÓN FÍSICA: un relato de experiencia - Natal / RN
}

\section{RESUMEN}

Después del lanzamiento del Portal deBase Nacional Comum Curricular (BNCC) y apertura a la aportes, un cronograma propuesto en el ámbito estatal, se ha establecido para que el estado del Rio Grande do Norte y sus municipios pudieran organizarse con el fin de movilizar sus profesores, alentándolos a que contribuyan a la construcción de este documento. Tratando de satisfacer estas demandas, proponemos, como un equipo de asesoramiento pedagógico del grupo de Educación Física de la Secretaria Municipal de Educação de Natal, el Foro de debate sobre BNCC a través del programa de Educación Continua para los profesores en el ejercicio de dicha Secretaría. Así, el Foro tuvo la intención de llevar a cabo una reflexión crítica sobre él BNCC y trae el profesor como colaborador de esta construcción democrática.En tal sentido, hemos articulado con el profesorado del Departamento de Educación Física de la Universidade Federal do Rio Grande do Norte que tuvo lugar en noviembre del año 2015, presentados en este Informe de Experiencia.

Palabras clave: Base Nacional; Formación Continua; Educación Física Escolar. 